\title{
Long-term Disease Course of Crohn's Disease: Changes in Disease Location, Phenotype, Activities, and Predictive Factors
}

\author{
Choong Wui Cho ${ }^{1}$, Myung-Won You' ${ }^{1}$, Chi Hyuk Oh², Chang Kyun Lee², and Sung Kyoung Moon ${ }^{1}$ \\ Departments of ${ }^{1}$ Radiology and ${ }^{2}$ Internal Medicine, Kyung Hee University Hospital, Seoul, Korea
}

\author{
Article Info \\ Received March 13, 2021 \\ Revised July 1, 2021 \\ Accepted July 13, 2021 \\ Published online August 31, 2021 \\ Corresponding Author \\ Myung-Won You \\ ORCID https://orcid.org/0000-0001-6262-5784 \\ E-mail funfun2020@khu.ac.kr
}

\begin{abstract}
Crohn's disease (CD) is a chronic destructive inflammatory bowel disease that affects young people and is associated with significant morbidity. The clinical spectrum and disease course of $\mathrm{CD}$ are heterogeneous and often difficult to predict based on the initial presentation. In this article, changes in the disease location, behavior, clinical course during long-term follow-up, and predictive factors are reviewed. Generally, four different patterns of clinical course are discussed: remission, stable disease, chronic relapsing disease, and chronic refractory disease. Understanding the long-term disease course of $C D$ is mandatory to reveal the underlying pathophysiology of the disease and to move toward a more optimistic disease course, such as remission or stability, and less adverse outcomes or devastating sequelae. (Gut Liver 2022;16:157-170)
\end{abstract}

Key Words: Crohn disease; Inflammatory bowel disease; Disease course; Recurrence; Prognosis

\section{INTRODUCTION}

Crohn's disease (CD) is a chronic condition that can affect any site of the gastrointestinal tract, with a wide spectrum of severity and variable disease course. ${ }^{1} \mathrm{CD}$ is traditionally known as a more prevalent disease in the Western world; however, the incidence of CD in Asia is increasing with the increase in the degree of urbanization from the 21st century onwards. ${ }^{2}$ Most patients with CD experience a waxing and waning clinical course of relapse and remission, and develop cumulative structural damage to the bowel over time. ${ }^{3}$ However, changes in the disease phenotype and severity are frequently heterogeneous and unpredictable for each patient. The evolution of anti-tumor necrosis factor (TNF) therapy improves the clinical outcomes of CD patients, such as clinical remission, steroid sparing, and mucosal healing. ${ }^{4}$ Anti-TNF therapy improved patients' outcomes in terms of achievement of targets of treatment and modification of the natural history of the disease in a higher percentage of patients in conjunction with immunosuppressive medication. Nonetheless, primary nonresponse or loss of response (LOR) to anti-TNF therapy remains frequent, leading to significant morbidity. ${ }^{5}$ There are few data regarding the long-term course of CD during lifelong treatment and monitoring. In this article, we elaborate on the changes in disease patterns, long-term clinical course, and predictive factors.

\section{LONG-TERM DISEASE COURSE OF CD AND ITS PREDICTIVE FACTORS}

\section{Changes in disease location over time}

Many reports have revealed that disease location remains relatively stable during the long-term disease course. Data on changes in disease location during the 10-year follow-up period are shown in Table 1. According to some Western studies, isolated colonic disease (L2) seems to have increased. ${ }^{6,7}$ Overall, the ileocolic area (L3) has been found to be the most frequently affected location in both Asian and Western studies. ${ }^{2,8-11}$ In a recent Asian-Pacific study conducted in eight countries across Asia and Australia, the distribution of disease location was almost the same. ${ }^{2}$ On the other hand, a Japanese study on pediatric CD patients demonstrated more frequent ileocolic (L3) and upper gastrointestinal (L4) involvement, and less colonic (L2) involvement compared with a European pediatric study based on a multicenter registry. ${ }^{15}$ Thia et al. ${ }^{14}$ re- 
Table 1. Changes in Disease Locations Over Time Based on the Montreal Classification: Long-term Follow-up Result (About 10-Year Period)

\begin{tabular}{|c|c|c|c|c|}
\hline Author (year) & Country & Location & Baseline, \% & 10 Years, $\%$ \\
\hline \multicolumn{5}{|l|}{ Asian countries } \\
\hline \multirow[t]{4}{*}{ Chow et al. $(2007)^{12}$} & Hong Kong & L1 & 11 & 0 \\
\hline & & L2 & 35 & 33 \\
\hline & & L3 & 54 & 67 \\
\hline & & L4 & 55.9 & 57.1 \\
\hline \multirow[t]{3}{*}{ Ye et al. $(2010)^{11}$} & South Korea & L1 & 24.4 & 24.4 \\
\hline & & L2 & 8.3 & 8.3 \\
\hline & & L3 & 67.3 & 67.3 \\
\hline \multirow[t]{4}{*}{ Makharia et al. $(2012)^{10}$} & India & L1 & 28.9 & \\
\hline & & L2 & 31.4 & \\
\hline & & L3 & 39.6 & \\
\hline & & L4 & 5.8 & \\
\hline \multirow[t]{4}{*}{ Ng et al. $(2013)^{2}$} & Asian-Pacific & L1 & $31 / 31 *$ & \\
\hline & & L2 & $24 / 24^{*}$ & \\
\hline & & L3 & $45 / 45^{*}$ & \\
\hline & & L4 & $5 / 5^{*}$ & \\
\hline \multirow[t]{4}{*}{ Kalaria et al. $(2016)^{8}$} & India & L1 & 28.9 & 36.8 \\
\hline & & L2 & 31.5 & 21 \\
\hline & & L3 & 39.4 & 42.2 \\
\hline & & L4 & 5.2 & 5.2 \\
\hline \multicolumn{5}{|l|}{ Western countries } \\
\hline \multirow[t]{3}{*}{ Louis et al. $(2001)^{13}$} & Belgium & L1 & 44.8 & 43.3 \\
\hline & & L2 & 26.7 & 23.3 \\
\hline & & L3 & 24.2 & 30 \\
\hline \multirow[t]{4}{*}{ Tarrant et al. (2008) } & New Zealand & L1 & 32 & 35 \\
\hline & & L2 & 49 & 41 \\
\hline & & L3 & 19 & 22 \\
\hline & & L4 & 0.6 & 2 \\
\hline \multirow[t]{4}{*}{ Solberg et al. $(2007)^{6}$} & Norway & L1 & 27 & 25.9 \\
\hline & & L2 & 48.5 & 47.7 \\
\hline & & L3 & 22.7 & 24.3 \\
\hline & & L4 & 1.7 & 2 \\
\hline \multirow[t]{4}{*}{ Lakatos et al. (2009) ${ }^{9}$} & Hungary & L1 & 22 & 18.2 \\
\hline & & L2 & 29.1 & 36.8 \\
\hline & & L3 & 47.3 & 44.4 \\
\hline & & L4 & 6.4 & 0.5 \\
\hline \multirow[t]{4}{*}{ Thia et al. $(2010)^{14}$} & USA & L1 & 45.1 & 42.5 \\
\hline & & L2 & 32 & 28.8 \\
\hline & & L3 & 18.6 & 23.2 \\
\hline & & L4 & 4.2 & 5.5 \\
\hline
\end{tabular}

L1, ileal disease; L2, colonic disease; L3, ileocolic disease; L4, upper gastrointestinal involvement.

*Asian/Pacific.

ported that only 20 patients $(6.5 \%)$ had a change in disease extent between baseline and observation of their maximal extent. In a Korean retrospective study, disease location did not change from the initial diagnosis to the last followup evaluation in any patient. ${ }^{11}$ In contrast, a Danish cohort study revealed that $24 \%$ of patients experienced location changes. ${ }^{16}$ The localization of the disease in different intestinal sites may be directly influenced by genetic and familial factors. ${ }^{1718}$ Bayless et al. ${ }^{19}$ reported high concordance for bowel location and clinical type within families. Specific genes have been reported; for example, $\mathrm{CD}$ patients with NOD2 or CARD15 gene mutations are susceptible to ileal disease, whereas the HLA-DRB1 allele is associated with pure colonic disease. ${ }^{17}$

\section{Changes in phenotypes over time}

When we examined the results of phenotypic changes in several reports, we found an obvious tendency of disease behavioral changes from simple inflammatory diseases to increased portions of complexity, either stricturing/penetrating or both diseases (Table 2). Many studies reported a complicated disease phenotype (B2/B3) of over $50 \%$ in a 10-year follow-up, compared to those in the baseline, which was approximately one-third. Cosnes et al. ${ }^{20}$ re- 
ported the highest proportion of complex disease phenotypes $(88 \%)$ at the end of a 20 -year follow-up, although the proportion of $\mathrm{B} 2 / \mathrm{B} 3$ was already over $50 \%$ at baseline. The initial need for steroids, age at diagnosis below 40 years, perianal disease, weight loss $>5 \mathrm{~kg}$ at diagnosis, small bowel location of disease, smoking, early azathioprine (AZA), or AZA/biological therapy are common predictive factors. ${ }^{6,921,22}$ In a recent study in Denmark, the proportion of $\mathrm{B} 2 / \mathrm{B} 3$ phenotypes at a 7 -year follow-up was $31 \%$, which had increased from baseline (17\%); nevertheless, it was improved compared to the reports of studies carried out in early $2000 .{ }^{16}$ This might be related to the increasing diagnosis of inflammatory disease phenotype and earlier use of biologics in recent years, although the exact cause needs to be verified.

\section{Clinical course according to changes in disease activity}

The clinical course of the disease can be classified into four different patterns in terms of the severity of bowel symptoms from diagnosis to the entire follow-up period. According to previous studies based on population-based prospective cohorts from Western countries (IBSEN study), ${ }^{6,23}$ the different patterns in the clinical course of $\mathrm{CD}$ were remission, aggravation, continuous refractory, and chronic relapsing. The percentages of each category were 43\% (remission), 3\% (aggravation), 19\% (chronic refractory), and 32\% (chronic relapsing). In this early 1990s cohort, the majority of the patients received oral 5-aminosalicylic acid and systemic steroids (73\% to $88 \%$ ) with $21 \%$ to $26 \%$ receiving AZA and only $4 \%$ receiving TNF blockers. ${ }^{6}$ Nowadays, the pattern of the clinical course should be modified according to the more prevalent and earlier use of TNF blockers as either monotherapy or combination therapy with immunosuppressants (IMS). Hence, salvaged cases from aggravation, refractory, or relapsing towards properly controlled disease course such as remission, improved, or stable disease will increase. In a recent prospective population-based cohort study, a significant portion of the patients was treated with biologics (23\%) and IMS (69\%), and the results showed a considerably more stable clinical course compared to previous reports. ${ }^{24}$ In this review, the clinical course of $\mathrm{CD}$ was defined partly based on the four disease activity patterns by Solberg et al. ${ }^{6}$ However, with modifications in consideration of recent treatment strategies, $\mathrm{CD}$ has now been categorized into the follow-

Table 2. Changes to Complicated Phenotypes (B2/B3) from Simple Inflammatory Phenotype (B1) Based on the Montreal Classification: Long-term Follow-up Result ( $\geq 10$ Years)

\begin{tabular}{|c|c|c|c|c|}
\hline Author (year) & Country & Phenotype & Baseline, \% & $\geq 10$ Years, $\%$ \\
\hline \multicolumn{5}{|l|}{ Asian countries } \\
\hline \multirow[t]{2}{*}{ Chow et al. $(2007)^{12}$} & Hong Kong & B1 & 67 & 43 \\
\hline & & B2/B3 & 33 & 57 \\
\hline \multirow[t]{2}{*}{ Das et al. $(2009)^{25}$} & India & B1 & 51 & \\
\hline & & B2/B3 & 49 & \\
\hline \multirow[t]{2}{*}{ Ye et al. $(2010)^{11}$} & South Korea & B1 & 68.7 & 49.3 \\
\hline & & B2/B3 & 31.3 & 50.7 \\
\hline \multirow[t]{2}{*}{ Makharia et al. $(2012)^{10}$} & India & B1 & 66.8 & \\
\hline & & B2/B3 & 33.2 & \\
\hline \multirow[t]{2}{*}{$\mathrm{Ng}$ et al. $(2013)^{2}$} & Asian-Pacific & B1 & $66 / 88^{*}$ & \\
\hline & & B2/B3 & $36 / 12^{*}$ & \\
\hline \multirow[t]{2}{*}{ Kalaria et al. $(2016)^{8}$} & India & B1 & 74.7 & 50 \\
\hline & & B2/B3 & 25.2 & 49.9 \\
\hline \multicolumn{5}{|l|}{ Western countries } \\
\hline \multirow[t]{2}{*}{ Cosnes et al. $(2002)^{20}$} & France & B1 & 40 & $12^{+}$ \\
\hline & & B2/B3 & 60 & $88^{+}$ \\
\hline \multirow[t]{2}{*}{ Louis et al. $(2001)^{13}$} & Belgium & B1 & 73.7 & 30.6 \\
\hline & & B2/B3 & 26.3 & 69.4 \\
\hline \multirow[t]{2}{*}{ Tarrant et al. (2008) ${ }^{7}$} & New Zealand & B1 & 73 & 44 \\
\hline & & B2/B3 & 27 & 56 \\
\hline \multirow[t]{2}{*}{ Solberg et al. $(2007)^{6}$} & Norway & B1 & 62 & 47 \\
\hline & & B2/B3 & 38 & 53 \\
\hline \multirow[t]{2}{*}{ Lakatos et al. (2009) } & Hungary & B1 & 58.3 & 28.3 \\
\hline & & B2/B3 & 41.7 & 71.7 \\
\hline \multirow[t]{2}{*}{ Thia et al. $(2010)^{14}$} & USA & B1 & 81.4 & 57.3 \\
\hline & & B2/B3 & 18.6 & 42.7 \\
\hline
\end{tabular}

B2, stricturing; B3, penetrating.

${ }^{*}$ Asian/Pacific; ${ }^{+} 20$ Years. 
ing four groups: remission, improved and stable, chronic relapsing, and refractory (Fig. 1).

\section{1) Remission}

Remission is defined as a Crohn's Disease Activity Index (CDAI) $\leq 150$ (Fig. 2). A Danish cohort study conducted during 1960 to 1978 showed that $45 \%$ of patients with CD were in an inactive disease state at the end of the follow-up period. ${ }^{26}$ Solberg et al. ${ }^{6}$ reported a similar rate of remission (43\%) in a 1990 to 1994 cohort after a 10-year follow-up. On the other hand, about $67 \%$ of the patients had a combination of years of relapse and years of remission within the first 8 years of initial diagnosis. ${ }^{27}$ Nevertheless, if an individual patient is in remission for 1 year, there is an $80 \%$ chance that this individual will remain in remission in the subsequent year. ${ }^{28}$ Based on a Markov model on a cohort prior to the introduction of anti-TNF therapy, a representative patient with CD would be expected to spend $24 \%$ of the time in medical remission and $41 \%$ of the time in postsurgical remission. ${ }^{29}$ An increased proportion of patients with $\mathrm{CD}$ have been receiving TNF agents in the biologics era, ${ }^{30}$ but there is scant data regarding the remission rate after a long-term follow-up period. Recent randomized trials have reported remission rates within 2 years of antiTNF therapy. According to Colombel et al., ${ }^{31}$ the remission rate at 6 months was $44.4 \%$ in the infliximab (IFX)-only group, compared to $56.8 \%$ for the combination therapy of IFX with IMS group and a similar remission rate in 1 year in the SONIC trial. The 1-year steroid-free remission rate after IFX therapy was $40 \%$ to $55.6 \%$ in the other trials. ${ }^{32,33}$ Overall, remission rates in recent studies are similar to those in past studies ( $43 \%$ to $45 \%$ ) conducted in the $1990 \mathrm{~s}$, although the remission rates in recent trials are from shortterm results showing the remission rate of induction treatment. However, the remission rate of combination therapy of IFX with IMS (55.6\% to 57.5\%) was slightly superior to that of IFX-only therapy in recent trials, ${ }^{31,32,34}$ and these results need to be further verified.

\section{(1) Deep remission}

Deep remission is defined as combined endoscopic and clinical remission. ${ }^{35}$ The therapeutic paradigm in CD has shifted from a mere symptom-oriented approach, aiming to heal the underlying inflammation and prevent long-term structural complications. Selecting Therapeutic Targets in Inflammatory Bowel Disease (STRIDE) initiative has proposed this "treat-to-target" concept, that is, to achieve clinical/patient-reported outcome remission plus endoscopic/radiologic remission. ${ }^{35}$ The STRIDE guidelines recommend achieving both clinical and endoscopic
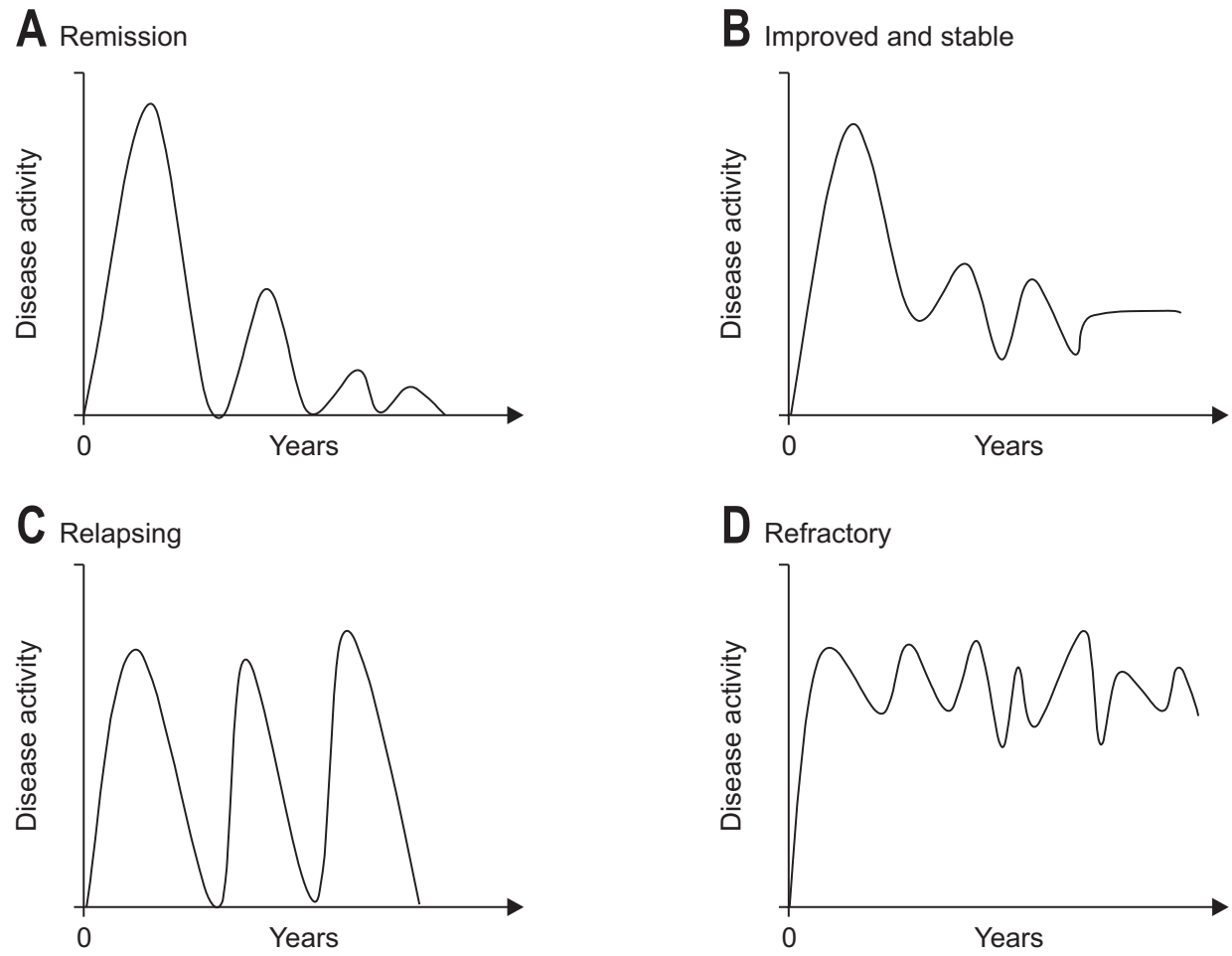

Fig. 1. Graphs representing four patterns of the long-term disease courses. (A) Remission: decrease in the severity of bowel symptoms during the follow-up period. (B) Improved and stable: decrease in the severity of bowel symptoms, but mild residual activity or sequelae, not disturbing everyday life. (C) Relapsing: flaring of bowel symptoms after achieving clinical remission during the follow-up period. (D) Refractory: chronic continuous bowel symptoms during the follow-up period. 

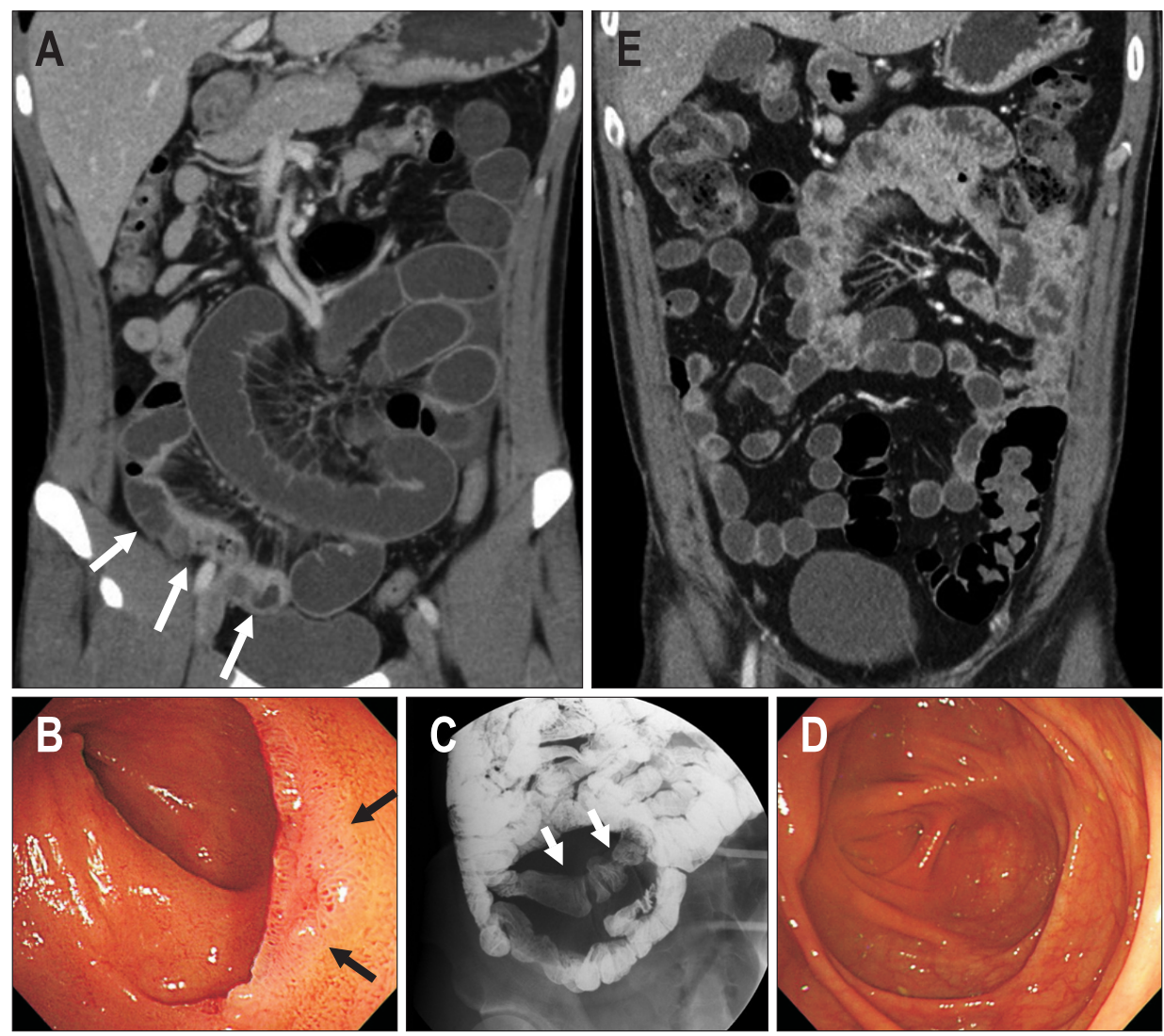

Fig. 2. A 30-year-old man in remission after long-term follow-up. (A) Initial small bowel enterography showed active inflammation in the distal and terminal ileum and inflammatory stenosis in the distal ileum (white arrows). The patient was treated with steroid induction followed by azathioprine maintenance. (B) Initial endoscopy revealed shallow ulcers in the terminal ileum, and a biopsy revealed chronic granulomatous inflammation (black arrows). (C) A small bowel series at the 2-year follow-up showed chronic scarring in the distal ileum (white arrows), without active lesion. (D, E) At the 7-year follow-up, the patient was in clinical remission with no active lesions identified on both computed tomography and endoscopy.

remission (mucosal healing) to prevent adverse long-term outcomes and disability. Mucosal healing is best associated with favorable clinical symptomatic remission and diseasemodifying outcomes such as hospitalization, surgical intervention, and quality of life..$^{36,37}$ Recently, STRIDE-II has updated the 2015 STRIDE recommendations, and restoration of quality of life and absence of disability have been added to endoscopic remission as long-term targets. ${ }^{38}$ Moreover, transmural healing assessed using cross-sectional imaging has been recommended as an adjunctive goal, although it is not a formal treatment target. After the application of the treat-to-target concept, the remission rate was lowered; deep remission was achieved in about $16 \%$ of patients with moderate-to-severe CD in the EXTEND trial ${ }^{39}$ and in 39\% of patients with early $\mathrm{CD}$ who were immunomodulatory and anti-TNF naïve in the SONIC trial. ${ }^{40}$

\section{(2) Surgical remission}

Surgical remission is another way to achieve remission. Surgery resulted in a longer duration of remission, suggesting that earlier surgery might be more beneficial from an economic perspective. ${ }^{29}$ Patients with $\mathrm{CD}$ who underwent surgery at diagnosis for acute abdomen showed a lower risk of reoperation and less use of steroids and IMS during follow-up than those who did not undergo surgery at diagnosis. ${ }^{41}$ On the other hand, surgery around the diagnosis (until 6 months) is clearly the result of complications already present at diagnosis and is more representative of the initial patient characteristics than a real outcome measure. ${ }^{42}$ Recent data suggest that surgery rates decreased prior to the advent of biologics, ${ }^{43-45}$ but the results were not confirmed in all studies, and the causative role is unproven. Surgery as an outcome parameter will be discussed later.

\section{(3) Predictors for maintaining remission}

Clinical parameters reflecting mild inflammation, such as a lower CDAI and non-stricturing and non-penetrating behaviors, were associated with mid- to long-term responsiveness to steroids. ${ }^{46}$ A prospective observational study from Italy reported that postinduction fecal calprotectin combined with weighted pediatric CDAI are predictors of 1 -year clinical and endoscopic remission to IFX in pediat- 
ric $\mathrm{CD}^{47}$ Although previous studies have reported comparable effectiveness of elemental diet to steroid use ${ }^{48}$ and the role of diet control in prolonging remission, ${ }^{49}$ nutritional therapy is regarded as only appropriate for adjunctive treatment to support nutrition, unlike the management of pediatric/adolescent $\mathrm{CD} .^{50}$

\section{2) Improved and stable}

Stable disease refers to a case with decreased severity of bowel symptoms during the follow-up period, but with mild residual activity or sequelae, as shown in the radiological or endoscopic assessment, not disturbing everyday life (Fig. 3). This is our potential explanation of cases showing discrepancies according to comprehensive assessments of biochemical, radiologic, and endoscopic parameters. Therefore, improved and stable disease includes cases in clinical remission but not in endoscopic and/or radiologic remission. According to a recently published report by Wintjens et al., ${ }^{51}$ a "mild chronic intermittent pattern" would be similar to this category among their six disease activity patterns. They defined six disease patterns according to the frequency of active diseases during the 10-year follow-up period, and "mild chronic intermittent pattern" was defined as five or fewer quarters of disease activity. On the other hand, clinical symptoms correlate poorly with the actual mucosal disease activity. ${ }^{52}$ Approximately one in two patients with $\mathrm{CD}$ in clinical remission had endoscopic and/or radiologic signs of residual CD activity, while one in five patients with endoscopic and biomarker remission reported persistent clinical symptoms. ${ }^{31}$ Colonic disease usually has many symptoms with frequent extraintestinal manifestations, whereas ileal disease can remain latent for several years. ${ }^{53}$ However, there is no relationship between the symptoms and the progression of anatomic damage. Strictures and fistulas can develop over the years without any symptoms. Small bowel disease might be complicated by an abscess, fistula, or stricture, whereas colonic disease can remain uncomplicated or inflammatory for many years. ${ }^{54}$ Therefore, endoscopic and/or radiological evaluation of disease activity and structural complications is important, especially for patients with small bowel lesions. Endoscopic assessment can confirm mucosal healing in the ileocolon; however, more proximal small bowel lesions remain inaccessible to conventional ileocolonoscopic techniques. Thus, non-invasive monitoring techniques such as computed tomography/magnetic resonance enterography (CTE/MRE), bowel ultrasound, or capsule endoscopy are crucial for accurate disease assessment. ${ }^{55}$ Small bowel capsule endoscopy has a high negative predictive value and is superior to other modalities (small bowel follow through, CTE or MRE) for diagnosing small bowel $\mathrm{CD}^{56}$ Gastrointestinal obstruction and strictures are contraindications for small bowel capsule endoscopy due to the risk of capsule retention. However, the capsule retention risk in patients with suspected CD without obstructive symptoms and without known stenosis is low, with a retention rate of only $1.6 \%$ compared to $13 \%$ in patients with established $\mathrm{CD}^{57}$ Patients with $\mathrm{CD}$ with no demonstrable bowel symptoms but remaining chronic sequelae such as stricture or fistula can be classified into this category, although there are few data regarding their proportion, management plan, or prognosis.

\section{(1) Predictors for benign course}

Data regarding benign courses are scarce compared to those regarding unfavorable courses. Factors associated
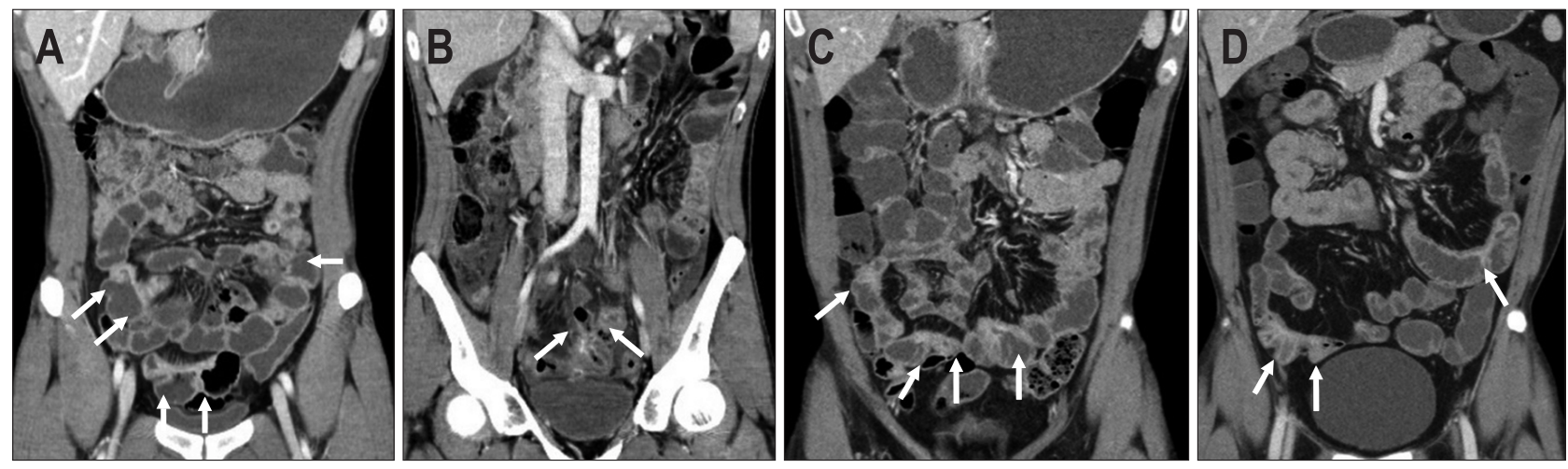

Fig. 3. A 31-year-old man showing an improved and stable course. (A) Initial computed tomography (CT) showed active inflammation involving both the jejunum and ileum (arrows). The patient was treated with steroid induction followed by azathioprine maintenance. (B) At the 2-year follow-up, CT revealed aggravated active inflammation involving the entire small bowel and development of a perienteric abscess in the pelvic ileum (arrows). Diffuse peritoneal infiltration and ascites are also observed, suggesting peritonitis. Due to aggravated symptoms and radiologic findings, infliximab therapy was started in combination with azathioprine. (C) At the 4-year follow-up, CT showed improved active inflammation of the small bowel as well as resolved perienteric abscess and peritonitis (arrows). Residual activity in the ileum was seen. (D) At the 9-year follow-up, mild activity remained in the small bowel (arrows), although the patient was symptom-free. 
with non-severe 15-year clinical course, defined as clinically inactive disease for greater than 12 years, less than one intestinal resection without permanent stoma and no death, were non-smoking status, rectal sparing, high educational level, older age, and longer disease duration. ${ }^{58}$

\section{3) Chronic relapsing}

Maintenance of remission in CD should last at least 12 months according to the recommendations of the European Crohn's and Colitis Organisation. ${ }^{59}$ Relapse is defined as a flare of symptoms in an established CD patient in clinical remission. Studies usually define relapse as CDAI $>150$ or reappearance of symptoms requiring treatment modification, hospitalization, or surgery (Fig. 4). ${ }^{60}$ In clinical practice, relapse is confirmed by laboratory parameters, imaging, or endoscopy. Early relapse is defined as relapse within an arbitrary period of $<3$ months after achieving remission in a particular therapy. ${ }^{50}$ Based on the pattern of relapse, they can be categorized as infrequent $(<1 /$ year) or frequent $(>2 /$ year $) .{ }^{27}$

Relapse rates in several previous studies ranged from $11 \%$ to $58 \%,{ }^{60}$ while studies in the 2000 s exhibited higher relapse rates (31\% to $58 \%){ }^{61,62}$ Recent studies in the 2010 s exhibited lower relapse rates (11\% to $27 \%){ }^{63,64}$ These changes in relapse rates over time may have been caused by changes in medical treatments. A larger proportion of IMS and biologics were prescribed for CD patients in recent studies, whereas mainly aminosalicylic acids were prescribed for patients in the earlier 2000s. Although Laharie et al. ${ }^{65}$ reported a relapse rate of $46 \%$, a slightly higher rate than other recent studies using biologics treatment, their study population included steroid-refractory
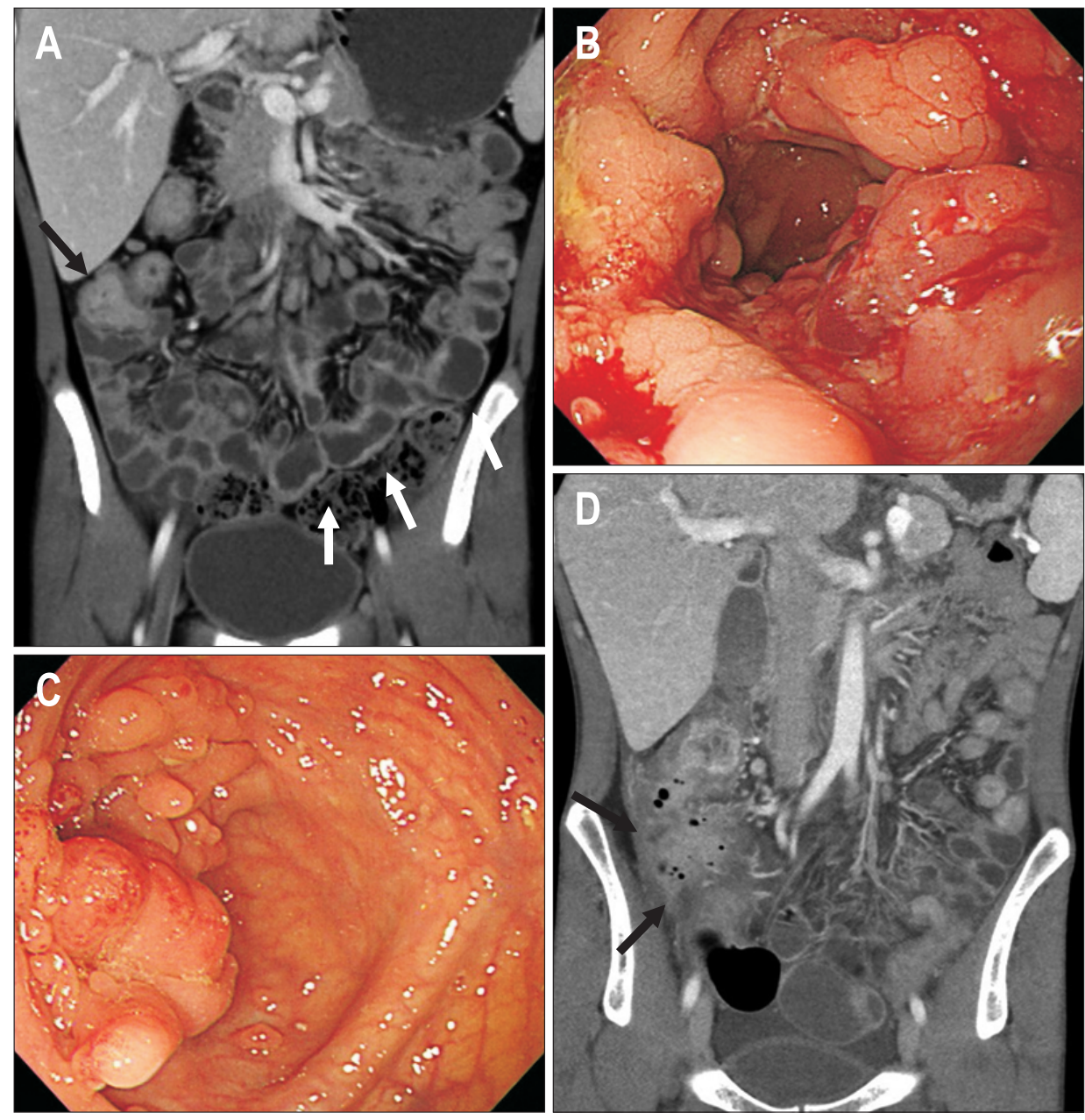

Fig. 4. A 14-year-old man showed chronic relapsing disease. (A) Initial computed tomography (CT) showed long segmental active inflammation in the entire small bowel (white arrows), ileocolic region, and right colon (black arrow). Due to severe activity, a combination of infliximab and azathioprine therapy was initiated. (B) Initial endoscopy also revealed severe activity involving longitudinal ulcerations, mucosal inflammation, and inflammatory polyps. (C) At the 2-year follow-up, endoscopy shows improved disease with no ulcers, inflammation and only remaining hyperplastic polyps. (D) The 10-year follow-up CT revealed a pericecal abscess with aggravated active inflammation in the ileocolic region despite a regimen change to ustekinumab (black arrows). The patient underwent right hemicolectomy to remove the ileocecal abscess. 
CD patients.

At the time of the initial diagnosis of $\mathrm{CD}$, induction therapy is necessary for patients exhibiting signs and symptoms of active disease. ${ }^{27}$ Once remission is achieved, patients are placed on maintenance therapy to ensure that remission is maintained for the longest possible period. ${ }^{27}$ Failure of maintenance therapy results in disease relapse. The majority of patients who were treated with corticosteroids to induce remission usually relapsed within 1 year without specific effective maintenance therapy. ${ }^{28}$ Although sulfasalazine and mesalamine are not effective agents in the maintenance of remission, IMS such as thiopurines, methotrexate, and TNF blockers are effective in the maintenance of CD remission. ${ }^{66}$ Despite the increasing use of IMS and TNF blockers, the remission rate has remained unchanged during the last decades (approximately 43\% to $45 \%$ ) and the improvement of the natural course of CD is still questionable. However, treatment options have been stratified according to comprehensive risk assessments, including initial disease activity, extent, and poor prognostic factors. The initial treatment of relapse should be based on previously successful therapies. ${ }^{50}$ However, several factors should be reassessed while deciding the treatment strategy for relapsing disease. These include time to relapse, initial therapy resulting in optimal response, adverse effects of current therapy, adherence to the prescribed therapy, and concurrent therapy. In case of early relapse, opinions remain divided on whether to use the same treatment to induce remission and taper more slowly or to use more potent induction therapy, and usually it necessitates the initiation of IMS to prevent future relapse. ${ }^{50}$ Moderate-to-severe relapsing disease warrants initiation of TNF blockers, and concurrent therapy with IFX and AZA is also noted to be more effective than either therapy alone..$^{50,67}$

Relapse during TNF blocker treatment can be caused by a LOR. Patients who initially respond to anti-TNF induction regimen subsequently lose response and experience flare of symptoms necessitating dose escalation, switching of anti-TNF agents, or surgical intervention. ${ }^{5}$ LOR usually occurs within the first 12 months, and the rate of LOR after 12 months of anti-TNF therapy in CD patients ranges from $23 \%$ to $46 \%$ for both IFX and adalimumab. ${ }^{68,69}$ The annual risk of LOR is between $13 \%$ and $24 \%$ as judged by the need for dose intensification ${ }^{70}$ and $7 \%$ per year experience LOR despite dose intensification. ${ }^{69}$ The most investigated mechanism for LOR is the formation of antibodies against anti-TNF agents. Antibodies-to-IFX is associated with lower serum levels of the drug due to increased drug clearance. ${ }^{71}$ Management options for LOR include dose optimization such as dose increase or interval shortening, switching to another TNF blocker, and addition of another
IMS to restore effective TNF blockade. ${ }^{5} \mathrm{~A}$ recent randomized controlled trial reported that the addition of AZA to the switch of anti-TNF yielded higher survival rates without clinical failure and the occurrence of unfavorable pharmacokinetics in patients with immune-mediated LOR to the first anti-TNF. ${ }^{68}$ Furthermore, treatment with a third anti-TNF agent or even retreatment with a previously failed anti-TNF can confer sustained clinical response in one-third of patients. ${ }^{72}$ However, switching from anti-TNF to another biologic with a different mode of action may prove more beneficial. ${ }^{73}$ In this respect, agents targeting leukocyte trafficking, such as anti-integrin vedolizumab or agents targeting IL-12/23 (anti-p40 antibody) such as ustekinumab, can be used as the next step in therapy for moderate-to-severe disease relapse in patients who have an inadequate response to TNF blockers and/or IMS. ${ }^{27}$

\section{(1) Predictors for relapse}

Several clinical and environmental predictors of relapse have been reported, including younger age at diagnosis ( $<25$ years), perianal disease, terminal ileal location, ${ }^{6,22}$ disease location in the proximal small bowel/upper gastrointestinal tract, ${ }^{23}$ short period of remission before relapse (<6 months), ${ }^{74}$ oral contraceptive use ${ }^{75}$ and stress. ${ }^{76}$ According to the European Crohn's and Colitis Organisation, common factors associated with higher relapse risk following withdrawal of IMS or anti-TNF are smoking, elevated C-reactive protein level, elevated fecal calprotectin, fistularizing perianal disease, and short duration of remission. Patients with deep remission (clinical, biological, and endoscopic) have a lower risk of relapse after anti-TNF withdrawal, and maintenance of IMS treatment seems to reduce the risk of relapse. ${ }^{77}$ In pediatric CD patients, baseline anti-Saccharomyces cerevisiae antibody (glycan antibody) reactivity has been associated with earlier complications, relapsing disease, and the need for additional surgery. ${ }^{78}$

\section{4) Chronic refractory}

$\mathrm{CD}$ is generally distinguished by a sequence of flare-up episodes and remissions of varying durations, whereas $10 \%$ to $15 \%$ of patients undergo a chronic refractory disease course (Fig. 5). ${ }^{79}$ Refractory disease refers to individuals showing persistent clinical symptoms without a period of remission. This might have been caused by the failure of induction treatment. A short course of steroids is effectively used for the induction treatment of active disease, and anti-TNF induction is recommended to treat steroid-resistant CD or moderate-to-severe disease with poor prognostic factors. ${ }^{28,80}$ However, $20 \%$ of patients receiving corticosteroid therapy remained refractory to steroids at 1 year. Moreover, $36 \%$ of patients develop steroid dependence 

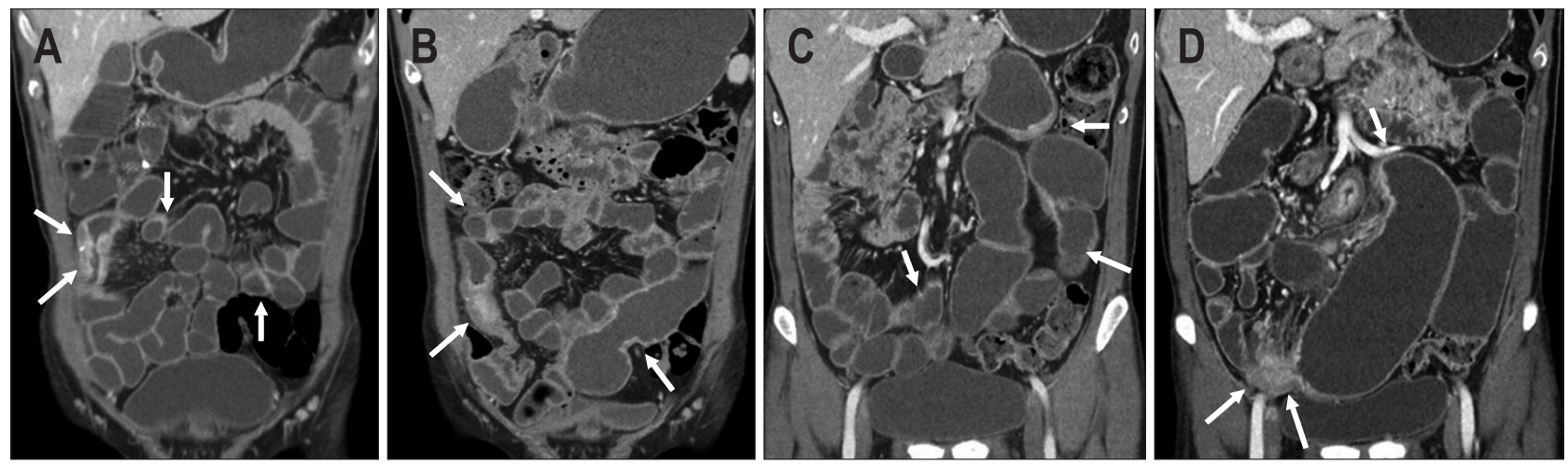

Fig. 5. A 36-year-old man showing a chronic refractory course. (A) Initial computed tomography (CT) showed multifocal active inflammation involving the small bowels (arrows). Azathioprine was initiated after the steroid induction. (B) At the 5-year follow-up, CT revealed persistent active inflammation involving the small bowel (right side arrows), and development of multifocal ileal stenosis (left arrow). Therefore, adalimumab was initiated despite improved symptoms. (C) At the 9-year follow-up, CT showed persistent activity in the small bowel (arrows) with ileal stenosis. The regimen was changed to infliximab due to adalimumab failure. (D) At the 10-year follow-up, CT showed aggravated active inflammation and stenosis involving the ileum (arrows). The regimen was changed to ustekinumab due to an insufficient trough level of infliximab. This patient showed refractory disease due to a poor response to biologics.

within the first year of therapy, and in these patients, steroids could not be tapered or discontinued without precipitation of a symptomatic relapse. ${ }^{81}$ Polymorphism in multidrug resistant 1, TNF, and migration inhibitory factor genes has been associated with steroid refractoriness. ${ }^{82,83}$ In steroid-refractory cases, other treatment options, including IMS, anti-TNF agents, ustekinumab, or vedolizumab, are available depending on the extent of the disease, prior disease response, and patient preference. ${ }^{27}$ A combination of steroids with an anti-TNF agent and an IMS is also possible and may improve outcomes. ${ }^{50}$ Anti-TNF refractory diseases can be caused by primary nonresponse. Primary nonresponse occurs in $20 \%$ to $40 \%$ of patients in clinical trials with both IFX and adalimumab, whereas lower rates of $10 \%$ to $20 \%$ primary nonresponse are generally reported in clinical real-life series. ${ }^{84}$ Several factors such as genetics, environmental insults, and the phenotype of the disease have been associated with an increased risk of primary nonresponse. ${ }^{85}$ Longer disease duration ( $>2$ years), small bowel extent of disease, smoking, and normal C-reactive protein have been reported to confer an increased risk of primary nonresponse. ${ }^{85}$ Certain genetic mutations and/or polymorphisms in the apoptosis-related genes of FAS-L, caspase- 9 and IBD5 loci can also be risk factors. ${ }^{84}$ Cases of familial $\mathrm{CD}$, that is, having a first-degree relative with the disease, are usually diagnosed at a younger age and have an increased risk of extraintestinal manifestations and refractory disease to medical therapy. ${ }^{60}$ However, the effect of family history is controversial because some studies have reported no significant influence of family history on the disease course ${ }^{86,87}$ Primary nonresponse to anti-TNF treatment is probably not a class-effect phenomenon. Switching to another IMS or another anti-TNF agent can still be ef- fective, referring to previous articles showing a $50 \%$ to $65 \%$ response rate after primary nonresponse to a first and/or second anti-TNF agent. ${ }^{72}$ Other options include treatment with ustekinumab or vedolizumab, or surgical intervention. Both ustekinumab and vedolizumab are effective as induction and maintenance treatments in patients with $\mathrm{CD}$, either naïve or exposed to anti-TNF. ${ }^{88} \mathrm{~A}$ recent French study compared the effectiveness and safety of ustekinum$\mathrm{ab}$ and vedolizumab in CD patients refractory to anti-TNF, and they suggested that ustekinumab is associated with a higher rate of clinical remission and treatment persistence. $^{89}$

\section{(1) Predictors for refractory disease}

In a previous prospective observational study from the United Kingdom, low drug concentration at week 14 after starting anti-TNF treatment (IFX and adalimumab) was the only factor associated with primary nonresponse. ${ }^{90}$ The authors explained that refractoriness to anti-TNF is mediated in part by the generation of anti-drug antibodies. Predictors of nonresponse to ustekinumab in treatmentrefractory $\mathrm{CD}$ are male sex, the presence of extraintestinal manifestations, the use of steroids at baseline, perianal disease, Harvey-Bradshaw index, and current opioid use. ${ }^{91,92}$

\section{Surgery}

Surgery and colectomy are among the most objective and extensively studied outcomes of CD. Major surgery and colectomy are needed in approximately $40 \%$ to $50 \%$ of $\mathrm{CD}$ cases within 10 years of diagnosis. ${ }^{93}$ The most common indications for surgical resection include medically refractory disease, bowel perforation, and persistent or recurrent obstruction. ${ }^{27}$ Recent data suggest that surgery rates 
decreased prior to the advent of biologics, parallel with the increased use of IMS and biological therapy. ${ }^{43,45}$ However, controversial results showing an association between the duration of AZA and anti-TNF and the risk for surgery, similar risk of hospitalization, surgery, and phenotype progression have also been reported. ${ }^{30,94}$ Therefore, improvement in natural history and disease outcome with the advent of biologics needs to be further investigated. Clinical predictors for surgery include age at onset, disease location, disease behavior, disease behavioral change, early use of AZA/biologics, perianal disease, smoking, and specialist care. ${ }^{42}$ While young age at diagnosis ( $<40$ years), terminal ileal or ileocolonic location, complicated disease behavior (stricturing and penetrating), and smoking were identified as risk factors, ${ }^{6,21,95}$ age over 40 years, isolated colonic localization, and gastroenterology specialist care were protective factors for surgery. ${ }^{6.96}$ The presence of NOD2 polymorphism has been associated with an earlier need for first surgery and a reduced postoperative disease-free interval. ${ }^{97}$

Data on changes in the natural history of $\mathrm{CD}$ indicate that surgery rates have declined in the last decade, partly associated with a greater proportion of patients with uncomplicated disease behavior, changes in patient monitoring, and different therapeutic strategies. ${ }^{98}$ However, further investigations are needed to assess whether objective patient monitoring or early administration of biologics leads to superior outcomes.

\section{SUMMARY}

Disease location remains stable with initial manifestation over time and is mostly determined by genetic/familial factors. Disease behavior evolves from simple inflammatory to complicated phenotypes, such as stricturing and/ or penetrating disease, in over $50 \%$ of CD patients after a long-term follow-up period. A comprehensive assessment of disease activity is mandatory during long-term treatment and monitoring. The long-term disease course can be categorized into four groups: remission, stable, chronic relapsing, and refractory diseases. With the introduction of biologics, the natural history of disease course and outcome seem to be enhanced with increased remission rates, decreased relapse rates, and decreased surgery rates. However, there are controversial results in several studies regarding this topic; therefore, more concrete research is required. Understanding changes in disease patterns, disease course, outcome, and predictive factors is necessary for the development of treatment strategies and better patient care in patients with $\mathrm{CD}$.

\section{CONFLICTS OF INTEREST}

No potential conflict of interest relevant to this article was reported.

\section{ACKNOWLEDGEMENTS}

This article is based on a scientific exhibition presented at the 76th Korean Congress of Radiology (KCR) on September 17-19, 2020, in Seoul, Korea.

\section{AUTHOR CONTRIBUTIONS}

Study concept and design: M.W.Y., C.K.L., C.H.O. Drafting of the manuscript: C.W.C., C.H.O. Supervision: M.W.Y., C.K.L., S.K.M. Writing-review \& editing: S.K.M., M.W.Y., C.H.O., C.K.L.

\section{ORCID}

Choong Wui Cho https://orcid.org/0000-0003-3181-6486 Myung-Won You https://orcid.org/0000-0001-6262-5784 Chi Hyuk Oh https://orcid.org/0000-0002-4382-5876 Chang Kyun Lee https://orcid.org/0000-0002-4279-3825 Sung Kyoung Moon https://orcid.org/0000-0003-4831-3439

\section{REFERENCES}

1. Aniwan S, Park SH, Loftus EV Jr. Epidemiology, natural history, and risk stratification of Crohn's disease. Gastroenterol Clin North Am 2017;46:463-480.

2. Ng SC, Tang W, Ching JY, et al. Incidence and phenotype of inflammatory bowel disease based on results from the AsiaPacific Crohn's and Colitis Epidemiology Study. Gastroenterology 2013;145:158-165.

3. Pariente B, Cosnes J, Danese S, et al. Development of the Crohn's disease digestive damage score, the Lémann score. Inflamm Bowel Dis 2011;17:1415-1422.

4. Targan SR, Hanauer SB, van Deventer SJ, et al. A short-term study of chimeric monoclonal antibody CA2 to tumor necrosis factor alpha for Crohn's disease. Crohn's Disease cA2 Study Group. N Engl J Med 1997;337:1029-1035.

5. Ben-Horin S, Chowers Y. Review article: loss of response to anti-TNF treatments in Crohn's disease. Aliment Pharmacol Ther 2011;33:987-995.

6. Solberg IC, Vatn MH, Høie O, et al. Clinical course in Crohn's disease: results of a Norwegian population-based 
ten-year follow-up study. Clin Gastroenterol Hepatol 2007;5:1430-1438.

7. Tarrant KM, Barclay ML, Frampton CM, Gearry RB. Perianal disease predicts changes in Crohn's disease phenotyperesults of a population-based study of inflammatory bowel disease phenotype. Am J Gastroenterol 2008;103:3082-3093.

8. Kalaria R, Desai D, Abraham P, Joshi A, Gupta T, Shah $S$. Temporal change in phenotypic behaviour in patients with Crohn's disease: do Indian patients behave differently from Western and other Asian patients? J Crohns Colitis 2016;10:255-261.

9. Lakatos PL, Czegledi Z, Szamosi T, et al. Perianal disease, small bowel disease, smoking, prior steroid or early azathioprine/biological therapy are predictors of disease behavior change in patients with Crohn's disease. World J Gastroenterol 2009;15:3504-3510.

10. Makharia GK, Ramakrishna BS, Abraham P, et al. Survey of inflammatory bowel diseases in India. Indian J Gastroenterol 2012;31:299-306.

11. Ye BD, Yang SK, Cho YK, et al. Clinical features and longterm prognosis of Crohn's disease in Korea. Scand J Gastroenterol 2010;45:1178-1185.

12. Chow DK, Leong RW, Lai LH, et al. Changes in Crohn's disease phenotype over time in the Chinese population: validation of the Montreal classification system. Inflamm Bowel Dis 2008;14:536-541.

13. Louis E, Collard A, Oger AF, Degroote E, Aboul Nasr El Yafi FA, Belaiche J. Behaviour of Crohn's disease according to the Vienna classification: changing pattern over the course of the disease. Gut 2001;49:777-782.

14. Thia KT, Sandborn WJ, Harmsen WS, Zinsmeister AR, Loftus EV Jr. Risk factors associated with progression to intestinal complications of Crohn's disease in a population-based cohort. Gastroenterology 2010;139:1147-1155.

15. Arai K, Kunisaki R, Kakuta F, et al. Phenotypic characteristics of pediatric inflammatory bowel disease in Japan: results from a multicenter registry. Intest Res 2020;18:412-420.

16. Lo B, Vester-Andersen MK, Vind I, et al. Changes in disease behaviour and location in patients with Crohn's disease after seven years of follow-up: a Danish population-based inception cohort. J Crohns Colitis 2018;12:265-272.

17. Cuthbert AP, Fisher SA, Mirza MM, et al. The contribution of NOD2 gene mutations to the risk and site of disease in inflammatory bowel disease. Gastroenterology 2002;122:867874.

18. Newman B, Silverberg MS, Gu X, et al. CARD15 and HLA DRB1 alleles influence susceptibility and disease localization in Crohn's disease. Am J Gastroenterol 2004;99:306-315.

19. Bayless TM, Tokayer AZ, Polito JM 2nd, Quaskey SA, Mellits ED, Harris ML. Crohn's disease: concordance for site and clinical type in affected family members. Potential hereditary influences. Gastroenterology 1996;111:573-579.

20. Cosnes J, Cattan S, Blain A, et al. Long-term evolution of disease behavior of Crohn's disease. Inflamm Bowel Dis 2002;8:244-250.

21. Beaugerie L, Seksik P, Nion-Larmurier I, Gendre JP, Cosnes J. Predictors of Crohn's disease. Gastroenterology 2006;130:650-656.

22. Loly C, Belaiche J, Louis E. Predictors of severe Crohn's disease. Scand J Gastroenterol 2008;43:948-954.

23. Henriksen M, Jahnsen J, Lygren I, et al. Clinical course in Crohn's disease: results of a five-year population-based follow-up study (the IBSEN study). Scand J Gastroenterol 2007;42:602-610.

24. Rönnblom A, Karlbom U. Clinical course of Crohn's disease in a population-based cohort in Uppsala County followed for 10 years. Scand J Gastroenterol 2020;55:1301-1307.

25. Das K, Ghoshal UC, Dhali GK, Benjamin J, Ahuja V, Makharia GK. Crohn's disease in India: a multicenter study from a country where tuberculosis is endemic. Dig Dis Sci 2009;54:1099-1107.

26. Binder V, Hendriksen C, Kreiner S. Prognosis in Crohn's disease: based on results from a regional patient group from the county of Copenhagen. Gut 1985;26:146-150.

27. Gajendran M, Loganathan P, Catinella AP, Hashash JG. A comprehensive review and update on Crohn's disease. Dis Mon 2018;64:20-57.

28. Lichtenstein GR, Hanauer SB, Sandborn WJ; Practice Parameters Committee of American College of Gastroenterology. Management of Crohn's disease in adults. Am J Gastroenterol 2009;104:465-483.

29. Silverstein MD, Loftus EV, Sandborn WJ, et al. Clinical course and costs of care for Crohn's disease: Markov model analysis of a population-based cohort. Gastroenterology 1999;117:49-57.

30. Peyrin-Biroulet L, Oussalah A, Williet N, Pillot C, Bresler L, Bigard MA. Impact of azathioprine and tumour necrosis factor antagonists on the need for surgery in newly diagnosed Crohn's disease. Gut 2011;60:930-936.

31. Colombel JF, Sandborn WJ, Reinisch W, et al. Infliximab, azathioprine, or combination therapy for Crohn's disease. $\mathrm{N}$ Engl J Med 2010;362:1383-1395.

32. Feagan B, McDonald JW, Panaccione R, et al. A randomized trial of methotrexate in combination with infliximab for the treatment of Crohn's disease. Gastroenterology 2008;135:294-295.

33. Lémann M, Mary JY, Duclos B, et al. Infliximab plus azathioprine for steroid-dependent Crohn's disease patients: a randomized placebo-controlled trial. Gastroenterology 2006;130:1054-1061.

34. D’Haens G, Baert F, van Assche G, et al. Early combined immunosuppression or conventional management in patients 
with newly diagnosed Crohn's disease: an open randomised trial. Lancet 2008;371:660-667.

35. Peyrin-Biroulet L, Sandborn W, Sands BE, et al. Selecting Therapeutic Targets in Inflammatory Bowel Disease (STRIDE): determining therapeutic goals for treat-to-target. Am J Gastroenterol 2015;110:1324-1338.

36. Rutgeerts P, Van Assche G, Sandborn WJ, et al. Adalimumab induces and maintains mucosal healing in patients with Crohn's disease: data from the EXTEND trial. Gastroenterology 2012;142:1102-1111.

37. Schnitzler F, Fidder H, Ferrante M, et al. Mucosal healing predicts long-term outcome of maintenance therapy with infliximab in Crohn's disease. Inflamm Bowel Dis 2009;15:1295-1301.

38. Turner D, Ricciuto A, Lewis A, et al. STRIDE-II: an update on the Selecting Therapeutic Targets in Inflammatory Bowel Disease (STRIDE) initiative of the International Organization for the Study of IBD (IOIBD): determining therapeutic goals for treat-to-target strategies in IBD. Gastroenterology 2021;160:1570-1583

39. Colombel JF, Rutgeerts PJ, Sandborn WJ, et al. Adalimumab induces deep remission in patients with Crohn's disease. Clin Gastroenterol Hepatol 2014;12:414-422.

40. Colombel JF, Reinisch W, Mantzaris GJ, et al. Randomised clinical trial: deep remission in biologic and immunomodulator naïve patients with Crohn's disease. A SONIC post hoc analysis. Aliment Pharmacol Ther 2015;41:734-746.

41. Latella G, Cocco A, Angelucci E, et al. Clinical course of Crohn's disease first diagnosed at surgery for acute abdomen. Dig Liver Dis 2009;41:269-276.

42. Vegh Z, Kurti Z, Golovics PA, Lakatos PL. Can we predict disease course with clinical factors? Curr Drug Targets 2018;19:791-797.

43. Jess T, Riis L, Vind I, et al. Changes in clinical characteristics, course, and prognosis of inflammatory bowel disease during the last 5 decades: a population-based study from Copenhagen, Denmark. Inflamm Bowel Dis 2007;13:481-489.

44. Oussalah A, Evesque L, Laharie D, et al. A multicenter experience with infliximab for ulcerative colitis: outcomes and predictors of response, optimization, colectomy, and hospitalization. Am J Gastroenterol 2010;105:2617-2625.

45. Rungoe C, Langholz E, Andersson M, et al. Changes in medical treatment and surgery rates in inflammatory bowel disease: a nationwide cohort study 1979-2011. Gut 2014;63:1607-1616.

46. Kim DH, Cheon JH, Park JJ, et al. Clinical outcomes and predictive factors for response after the first course of corticosteroid therapy in patients with Crohn's disease. Gut Liver 2013;7:58-65.

47. D’Arcangelo G, Oliva S, Dilillo A, et al. Predictors of longterm clinical and endoscopic remission in children with
Crohn disease treated with infliximab. J Pediatr Gastroenterol Nutr 2019;68:841-846.

48. Riordan AM, Hunter JO, Cowan RE, et al. Treatment of active Crohn's disease by exclusion diet: East Anglian multicentre controlled trial. Lancet 1993;342:1131-1134.

49. Jones VA, Dickinson RJ, Workman E, Wilson AJ, Freeman AH, Hunter JO. Crohn's disease: maintenance of remission by diet. Lancet 1985;2:177-180.

50. Gomollón F, Dignass A, Annese V, et al. 3rd European evidence-based consensus on the diagnosis and management of Crohn's disease 2016: part 1. Diagnosis and medical management. J Crohns Colitis 2017;11:3-25.

51. Wintjens D, Bergey F, Saccenti E, et al. Disease activity patterns of Crohn's disease in the first ten years after diagnosis in the population-based IBD South Limburg cohort. J Crohns Colitis 2021;15:391-400.

52. Jones J, Loftus EV Jr, Panaccione R, et al. Relationships between disease activity and serum and fecal biomarkers in patients with Crohn's disease. Clin Gastroenterol Hepatol 2008;6:1218-1224.

53. Watanabe K. Clinical management for small bowel of Crohn's disease in the treat-to-target era: now is the time to optimize treatment based on the dominant lesion. Intest Res 2020;18:347-354.

54. Oberhuber G, Stangl PC, Vogelsang H, Schober E, Herbst F, Gasche C. Significant association of strictures and internal fistula formation in Crohn's disease. Virchows Arch 2000;437:293-297.

55. Benitez JM, Meuwis MA, Reenaers C, Van Kemseke C, Meunier P, Louis E. Role of endoscopy, cross-sectional imaging and biomarkers in Crohn's disease monitoring. Gut 2013;62:1806-1816.

56. Hansel SL, McCurdy JD, Barlow JM, et al. Clinical benefit of capsule endoscopy in Crohn's disease: impact on patient management and prevalence of proximal small bowel involvement. Inflamm Bowel Dis 2018;24:1582-1588.

57. Cheifetz AS, Kornbluth AA, Legnani P, et al. The risk of retention of the capsule endoscope in patients with known or suspected Crohn's disease. Am J Gastroenterol 2006;101:2218-2222.

58. Cosnes J, Gower-Rousseau C, Seksik P, Cortot A. Epidemiology and natural history of inflammatory bowel diseases. Gastroenterology 2011;140:1785-1794.

59. Stange EF, Travis SP, Vermeire S, et al. European evidence based consensus on the diagnosis and management of Crohn's disease: definitions and diagnosis. Gut 2006;55 Suppl 1(Suppl 1):i1-i15.

60. Liverani E, Scaioli E, Digby RJ, Bellanova M, Belluzzi A. How to predict clinical relapse in inflammatory bowel disease patients. World J Gastroenterol 2016;22:1017-1033.

61. D’Incà R, Dal Pont E, Di Leo V, et al. Can calprotectin pre- 
dict relapse risk in inflammatory bowel disease? Am J Gastroenterol 2008;103:2007-2014.

62. Tibble JA, Sigthorsson G, Bridger S, Fagerhol MK, Bjarnason I. Surrogate markers of intestinal inflammation are predictive of relapse in patients with inflammatory bowel disease. Gastroenterology 2000;119:15-22.

63. García-Sánchez V, Iglesias-Flores E, González R, et al. Does fecal calprotectin predict relapse in patients with Crohn's disease and ulcerative colitis? J Crohns Colitis 2010;4:144152 .

64. Naismith GD, Smith LA, Barry SJ, et al. A prospective evaluation of the predictive value of faecal calprotectin in quiescent Crohn's disease. J Crohns Colitis 2014;8:1022-1029.

65. Laharie D, Mesli S, El Hajbi F, et al. Prediction of Crohn's disease relapse with faecal calprotectin in infliximab responders: a prospective study. Aliment Pharmacol Ther 2011;34:462-469.

66. Hanauer SB, Feagan BG, Lichtenstein GR, et al. Maintenance infliximab for Crohn's disease: the ACCENT I randomised trial. Lancet 2002;359:1541-1549.

67. Roblin X, Williet N, Boschetti G, et al. Addition of azathioprine to the switch of anti-TNF in patients with IBD in clinical relapse with undetectable anti-TNF trough levels and antidrug antibodies: a prospective randomised trial. Gut 2020;69:1206-1212.

68. Sandborn WJ, Colombel JF, Schreiber S, et al. Dosage adjustment during long-term adalimumab treatment for Crohn's disease: clinical efficacy and pharmacoeconomics. Inflamm Bowel Dis 2011;17:141-151.

69. Schnitzler F, Fidder H, Ferrante M, et al. Long-term outcome of treatment with infliximab in 614 patients with Crohn's disease: results from a single-centre cohort. Gut 2009;58:492500 .

70. Gisbert JP, Panés J. Loss of response and requirement of infliximab dose intensification in Crohn's disease: a review. Am J Gastroenterol 2009;104:760-767.

71. Bendtzen K, Geborek P, Svenson M, Larsson L, Kapetanovic MC, Saxne T. Individualized monitoring of drug bioavailability and immunogenicity in rheumatoid arthritis patients treated with the tumor necrosis factor alpha inhibitor infliximab. Arthritis Rheum 2006;54:3782-3789.

72. Allez M, Vermeire S, Mozziconacci N, et al. The efficacy and safety of a third anti-TNF monoclonal antibody in Crohn's disease after failure of two other anti-TNF antibodies. Aliment Pharmacol Ther 2010;31:92-101.

73. Ben-Horin S. Loss of response to anti-tumor necrosis factors: what is the next step? Dig Dis 2014;32:384-388.

74. Sahmoud T, Hoctin-Boes G, Modigliani R, et al. Identifying patients with a high risk of relapse in quiescent Crohn's disease. The GETAID Group. The Groupe d'Etudes Thérapeutiques des Affections Inflammatoires Digestives. Gut
1995;37:811-818.

75. Timmer A, Sutherland LR, Martin F. Oral contraceptive use and smoking are risk factors for relapse in Crohn's disease. The Canadian Mesalamine for Remission of Crohn's Disease Study Group. Gastroenterology 1998;114:1143-1150.

76. Bitton A, Dobkin PL, Edwardes MD, et al. Predicting relapse in Crohn's disease: a biopsychosocial model. Gut 2008;57:1386-1392.

77. Doherty G, Katsanos KH, Burisch J, et al. European Crohn's and Colitis Organisation topical review on treatment withdrawal ['Exit Strategies'] in inflammatory bowel disease. J Crohns Colitis 2018;12:17-31.

78. Amre DK, Lambrette P, Law L, et al. Investigating the hygiene hypothesis as a risk factor in pediatric onset Crohn's disease: a case-control study. Am J Gastroenterol 2006;101:1005-1011.

79. Munkholm P, Langholz E, Davidsen M, Binder V. Disease activity courses in a regional cohort of Crohn's disease patients. Scand J Gastroenterol 1995;30:699-706.

80. Wisniewski A, Danese S, Peyrin-Biroulet L. Evolving treatment algorithms in Crohn's disease. Curr Drug Targets 2018;19:782-790.

81. Lichtenstein GR. Approach to corticosteroid-dependent and corticosteroid-refractory Crohn's disease. Inflamm Bowel Dis 2001;7 Suppl 1:S23-S29.

82. Cucchiara S, Latiano A, Palmieri O, et al. Polymorphisms of tumor necrosis factor-alpha but not MDR1 influence response to medical therapy in pediatric-onset inflammatory bowel disease. J Pediatr Gastroenterol Nutr 2007;44:171-179.

83. Beaugerie L, Sokol H. Clinical, serological and genetic predictors of inflammatory bowel disease course. World J Gastroenterol 2012;18:3806-3813.

84. Ben-Horin S, Kopylov U, Chowers Y. Optimizing anti-TNF treatments in inflammatory bowel disease. Autoimmun Rev 2014;13:24-30.

85. Siegel CA, Melmed GY. Predicting response to anti-TNF agents for the treatment of Crohn's disease. Therap Adv Gastroenterol 2009;2:245-251.

86. Carbonnel F, Macaigne G, Beaugerie L, Gendre JP, Cosnes J. Crohn's disease severity in familial and sporadic cases. Gut 1999;44:91-95.

87. Henriksen M, Jahnsen J, Lygren I, Vatn MH, Moum B; IBSEN Study Group. Are there any differences in phenotype or disease course between familial and sporadic cases of inflammatory bowel disease? Results of a population-based follow-up study. Am J Gastroenterol 2007;102:1955-1963.

88. Sands BE, Feagan BG, Rutgeerts P, et al. Effects of vedolizumab induction therapy for patients with Crohn's disease in whom tumor necrosis factor antagonist treatment failed. Gastroenterology 2014;147:618-627.

89. Alric H, Amiot A, Kirchgesner J, et al. The effectiveness of 
either ustekinumab or vedolizumab in 239 patients with Crohn's disease refractory to anti-tumour necrosis factor. Aliment Pharmacol Ther 2020;51:948-957.

90. Kennedy NA, Heap GA, Green HD, et al. Predictors of antiTNF treatment failure in anti-TNF-naive patients with active luminal Crohn's disease: a prospective, multicentre, cohort study. Lancet Gastroenterol Hepatol 2019;4:341-353.

91. Dalal RS, Njie C, Marcus J, Gupta S, Allegretti JR. Predictors of ustekinumab failure in Crohn's disease after dose intensification. Inflamm Bowel Dis 2021;27:1294-1301.

92. Hoffmann P, Krisam J, Wehling C, et al. Ustekinumab: "Realworld" outcomes and potential predictors of nonresponse in treatment-refractory Crohn's disease. World J Gastroenterol 2019;25:4481-4492.

93. Bernstein CN, Loftus EV Jr, Ng SC, Lakatos PL, Moum B; Epidemiology and Natural History Task Force of the International Organization for the Study of Inflammatory Bowel Disease (IOIBD). Hospitalisations and surgery in Crohn's disease. Gut 2012;61:622-629.

94. Jeuring SF, van den Heuvel TR, Liu LY, et al. Improvements in the long-term outcome of Crohn's disease over the past two decades and the relation to changes in medical management: results from the population-based IBDSL cohort. Am J Gastroenterol 2017;112:325-336.

95. Sutherland LR, Ramcharan S, Bryant H, Fick G. Effect of cigarette smoking on recurrence of Crohn's disease. Gastroenterology 1990;98(5 Pt 1):1123-1128.

96. Nguyen GC, Nugent Z, Shaw S, Bernstein CN. Outcomes of patients with Crohn's disease improved from 1988 to 2008 and were associated with increased specialist care. Gastroenterology 2011;141:90-97.

97. Alvarez-Lobos M, Arostegui JI, Sans M, et al. Crohn's disease patients carrying Nod2/CARD15 gene variants have an increased and early need for first surgery due to stricturing disease and higher rate of surgical recurrence. Ann Surg 2005;242:693-700.

98. Golovics PA, Mandel MD, Lovasz BD, Lakatos PL. Inflammatory bowel disease course in Crohn's disease: is the natural history changing? World J Gastroenterol 2014;20:31983207. 